\title{
Injury incidence, characteristics and burden among female sub-elite futsal players: A prospective study with three-year follow-up
}

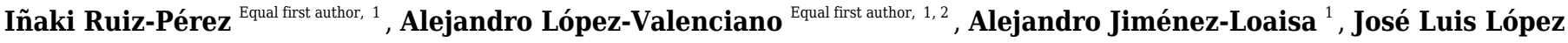 \\ Elvira $^{1}$, Mark De Ste Croix ${ }^{3}$, Francisco Ayala ${ }^{\text {Corresp. } 1,3}$ \\ ${ }^{1}$ Department of Sport Sciences, Sports Research Centre, Miguel Hernández University, Elche, Alicante, Spain \\ 2 Universidad Internacional Isabel I de Castilla, Burgos, Spain \\ ${ }^{3}$ School of Sport and Exercise, University of Gloucestershire, Gloucester, United Kingdom \\ Corresponding Author: Francisco Ayala \\ Email address: fayala@umh.es
}

The main purpose of the current study was to analyze the injury incidence, characteristics and burden among sub-elite female futsal players. Individual exposure to match play and training, injury incidence and characteristics (player position, injury mechanism, type of injuries, severity of injuries, recurrent versus new injuries, season variation of injury pattern) in a female futsal team were prospectively recorded for three consecutive seasons (2015-2018). Incidences were calculated per 1000 hours of exposure. A total of 30 injuries were reported during the three seasons within a total exposure of 4446.1 hours. The overall, match and training incidence of injuries were $6.7,6.4$ and 6.8 injuries/1000 hours of exposure, respectively. Most injuries had a non-contact mechanism (93\%), with the lower extremity being the most frequently injured anatomical region (5.62 injuries/1000 hours of exposure). The most common type of injury was muscle/tendon (4.9 injuries/1000 hours of exposure) followed by joint (non-bone) and ligament (1.3 injuries/1000 hours of exposure). The injuries with the highest injury burden were those that occurred at the knee (31.9 days loss/1000 hours exposure), followed by quadriceps (15.3 day loss/1000 hours) and hamstring (14.4 day loss/1000 hours) strains. The first few weeks of competition after pre-season and soon after the Christmas break were the time points when most injuries occurred. These data indicate that sub-elite female futsal players are exposed to a substantial risk of sustaining an injury. To reduce overall injury burden, efforts should be directed toward the design, implementation and assessment of preventative measures that target the most common diagnoses, namely, muscle/tendon and ligament injuries. 
4 Injury incidence, characteristics and burden among female sub-elite futsal players: A prospective study with three-year follow-up.

7 Iñaki Ruiz-Pérez ${ }^{1}$, Alejandro López-Valenciano ${ }^{1,2}$, Alejandro Jiménez-Loaisa ${ }^{1}$, José Luis López

8 Elvira $^{1}$, Mark De Ste Croix ${ }^{3}$, Francisco Ayala ${ }^{1,3^{*}}$

9

10 Running Head: Epidemiology of futsal injuries

11

12 1: Department of Sport Sciences, Sports Research Centre, Miguel Hernández University of Elche, 13 Elche, Alicante (Spain).

14 2: Universidad Internacional Isabel I de Castilla, Burgos (Spain)

15 3: School of Sport and Exercise, University of Gloucestershire, (Gloucester, United Kingdom).

18 *: Corresponding Author.

19 Francisco Ayala.

20 Email address: franciscoayalarodriguez@gmail.com . 


\section{Abstract}

24 The main purpose of the current study was to analyze the injury incidence, characteristics and

25 burden among sub-elite female futsal players. Individual exposure to match play and training,

26 injury incidence and characteristics (player position, injury mechanism, type of injuries, severity

27 of injuries, recurrent versus new injuries, season variation of injury pattern) in a female futsal

28 team were prospectively recorded for three consecutive seasons (2015-2018). Incidences were

29 calculated per 1000 hours of exposure. A total of 30 injuries were reported during the three

30 seasons within a total exposure of 4446.1 hours. The overall, match and training incidence of

31 injuries were 6.7, 6.4 and 6.8 injuries/1000 hours of exposure, respectively. Most injuries had a

32 non-contact mechanism (93\%), with the lower extremity being the most frequently injured

33 anatomical region (5.62 injuries/1000 hours of exposure). The most common type of injury was

34 muscle/tendon (4.9 injuries/1000 hours of exposure) followed by joint (non-bone) and ligament

35 (1.3 injuries/1000 hours of exposure). The injuries with the highest injury burden were those that

36 occurred at the knee (31.9 days loss/1000 hours exposure), followed by quadriceps (15.3 day

37 loss/1000 hours) and hamstring (14.4 day loss/1000 hours) strains. The first few weeks of

38 competition after pre-season and soon after the Christmas break were the time points when most

39 injuries occurred. These data indicate that sub-elite female futsal players are exposed to a

40 substantial risk of sustaining an injury. To reduce overall injury burden, efforts should be

41 directed toward the design, implementation and assessment of preventative measures that target

42 the most common diagnoses, namely, muscle/tendon and ligament injuries.

43 Key words: epidemiology, injury surveillance, muscle/tendon injuries, injury patterns,

44 prevention. 


\section{Introduction}

46

47

Futsal, the five-a-side version of associated football, is played worldwide with more than one million registered players all over the world (FIFA, 2007; Gorostiaga et al., 2009; Beato et al., 2017). Futsal requires players to perform on a reduced (usually indoor) pitch size (40 x $20 \mathrm{~m})$ and during two x 20 min periods (with time stopping at every dead ball and unlimited substitutions) a high number of repeated high intensity multiplanar movements such as sudden acceleration and deceleration, rapid changes of direction, tackling and kicking (Castagna et al., 2009; Beato, Coratella \& Schena, 2016; Naser, Ali \& Macadam, 2017). At top levels, the combination of these repeated high intensity movements that are performed during training and match play alongside current congested training and competitive calendars and exposure to contacts might place futsal players at high risk of injury. However, prior to implementing injury prevention programmes into everyday futsal training routines, it is essential to establish the extent of the problem in terms of the incidence and characteristics of injuries (van Mechelen, Hlobil \& Kemper, 1992; Finch, 2006; Van Tiggelen et al., 2008).

Despite being one of the most played sport in several countries, a limited number of prospective epidemiological studies have been published investigating injuries sustained by elite futsal players (mainly during match play) (Ribeiro, Oliveira \& Costa, 2006; Junge \& Dvorak, 2010; Angoorani et al., 2014; Hamid, Jaafar \& Ali, 2014; Álvarez Medina et al., 2016). These studies have reported incidence rates for male players ranging from 3.5 to 89.9 injuries per $1000 \mathrm{~h}$ of match play, most of them affecting the lower extremity with contusions of the lower leg and ankle sprains the most frequently diagnosed types of injury (Ribeiro, Oliveira \& Costa, 2006; Junge \& Dvorak, 2010; Angoorani et al., 2014; Hamid, Jaafar \& Ali, 2014; Álvarez Medina et al., 2016; Larruskain et al., 2018). However, it should be noted that among these epidemiological 
68 studies, only two (Angoorani et al., 2014; Hamid, Jaafar \& Ali, 2014) have reported incidence

69 data of female futsal players. Angoorani et al. (2014) showed an incidence rate in female players

70 of 10.7 injuries per $1000 \mathrm{~h}$ of match play during camps with the Iran national team (18 months of

71 follow-up), whereas Hamid et al. (2014) found an incidence rate of 19.7 injuries per $1000 \mathrm{~h}$ of

72 match play during the Malaysian national futsal league. In both studies, ankle sprains and

73 ligament ruptures were the most observed injuries, similar to what has been observed in other

74 team sports such as football (Hägglund, Waldén \& Ekstrand, 2009; Asker et al., 2018), handball

75 (Asker et al., 2018) and rugby (Peck et al., 2013). It is likely that the anatomical, hormonal and

76 neuromuscular sex-related differences (among other factors) may contribute to sex-specific

77 differences in injury incidence. Furthermore, only Angoorani et al. (2014) provided injury

78 incidence rates during training in male and female futsal players, reporting an incidence of 1.8

79 and 3.1 injuries per $1000 \mathrm{~h}$ of exposure, respectively. As the training volume (Almeida et al.,

80 1999) and the number of hours of high intensity training (Brooks et al., 2008) have been

81 significantly correlated with an increased risk of sustaining non-contact injuries in team sports

82 (mainly attributed to an acute and/or cumulative fatigue state), knowing the injury incidence

83 rates during futsal training may help coaches and physical trainers to identify if the training load

84 and content allows players to recover fully from match demands. None of the studies that have

85 provided epidemiological data of futsal-related injuries in male and female players have

86 calculated the injury burden (the product of severity [consequences] and incidence [likelihood])

87 and/or built a risk matrix. A risk matrix is a graph of injury severity plotted against injury

88 incidence with criteria incorporated into the graph for evaluating the level of risk, usually by

89 dividing the graph into some risk areas using descriptive or quantified incidence, severity and

90 risk evaluation categories (Fuller, 2018). 
91 Consequently, there is a clear need for more prospective epidemiological studies that inform

92 about injury incidence and burden in female futsal players. Identifying the most common and

93 burdensome futsal-related injuries, as well as how (traumatic or overuse) and when (matches or

94 training sessions) they usually occur would lead coaches, physical trainers and physiotherapists

95 to prioritise the application of specific measures to prevent or reduce the risk of sustaining such

96 injuries. Therefore, the main purpose of the current study was to analyze the injury incidence,

97 characteristics and burden among sub-elite female futsal players during three consecutive 98 seasons.

99

100

2. Method

$101 \quad$ 2.1 Participants

102 All female sub-elite futsal players from the same team that were playing in the Spanish second

103 division were prospectively followed during three consecutive seasons $(2015 / 16,2016 / 17$ and

104 2017/18) which covered the period between September and May. Twenty-two different female

105 futsal players participated in this study. However, as some players remained in the team for more

106 than one season, the total number of player seasons was 39 (2015/16: 14 players followed,

107 2017/17: 13 players followed, 2017/18: 12 players followed). All players had more than 5 years

108 of futsal experience. The team finished all three seasons in the top 10 of the league $\left(4^{\text {st }}, 6^{\text {st }}\right.$ and

$\left.1099^{\text {st }}\right)$. All players were verbally informed about the study procedures and provided written

110 informed consent. For players younger than 18 years old $(n=3)$, written informed consent was

111 also obtained from their parent or legal guardian. Players who left the team during the season

112 (e.g. due to transfer) were included in the analysis according to their time on the team. The

113 experimental procedures used in this study were in accordance with the Declaration of Helsinki 
114 and were approved by the University Office for Research Ethics (Órgano evaluador de

115 proyectos, Universidad Miguel Hernández de Elche) (DPS.FAR.02.14).

116

\section{$117 \quad 2.2$ Data collection}

118 The study design and data collection followed both the consensus on definitions and data

119 collection procedures for studies of football injuries outlined by the Union of European Football

120 Associations (UEFA) (Hägglund, Waldén \& Bahr, 2005) and the consensus document for

121 football injury surveillance studies (Fuller et al., 2006). An injury was defined as any physical

122 complaint sustained by a player that resulted from a futsal match or futsal training and where the

123 player was unable to participate in a match or training sessions on the day after the injury (time-

124 loss injury) (Fuller et al., 2006). The day on which an injury occurred was day 0 and was not

125 counted when determining the severity of an injury. If a player had to stop training or

126 participating in a match because of injury on 1 day but could participate the next day, the time

127 loss was recorded as zero days.

128 The club's medical staff (which remained the same for all three seasons), diagnosed, treated and

129 recorded all time-loss injuries on a standardised injury report form that was sent to the study

130 group each month. Specifically, the team was supported by one certified medical doctor, one

131 physical trainer and one physiotherapist. The doctor was the member of the medical staff who

132 assessed and diagnosed injured players through the use of clinical judgements (e.g.: physical

133 examination, posture and gait inspection, inspection and palpation of muscle bellies, etc.).

134 Diagnostic imaging techniques (e.g.: echography, magnetic resonance imaging and ultrasound

135 imaging) were also applied when it was needed. Although early treatment actions were delivered

136 as soon as possible when a player sustained an injury during training or competition, the initial 
137 assessment and diagnosis were often carried out within 12 hours to 4 days post-injury as some

138 signs of injury may arise a few hours or days later (Askling, Tengvar, Saartok \& Thorstensson,

139 2007). The physiotherapist administered the therapeutic exercises during the first stages of the

140 rehabilitation process. The physical trainer was responsible for introducing injured players to the

141 drills and skills that would be required to return to full participation in training and to be

142 available for match selection. A futsal player was considered injured until the medical staff

143 (upon agreement) allowed full participation in training and they were eligible for match play.

144 For all injuries that satisfied the inclusion criteria (time-loss injury), team medical staff provided

145 the following details to investigators: date of injury, moment (training or competition), player

146 position (goalkeeper or field player [lastwoman, wing or pivot]), injury mechanism (traumatic

147 [contact or non-contact] or overuse), injury location, type of injury (the specific injury diagnosis

148 was also recorded), extremity of the injury (dominant/non dominant), injury severity based on

149 lay off time ( 0 days [when a player could not participate fully on the day of an injury but was

150 available for full participation the next day], minimal [1-3 days], mild [4-7 days], moderate [8-28

151 days], severe [ $>28$ days] and career ending injury), whether it was a recurrence or new injury and

152 total time taken to resume full training and competition. Illnesses and any physical or mental

153 complaint that did not result from a futsal match or training were excluded. Individual player

154 exposure time in training and matches (friendly and competitive) were recorded daily in minutes

155 by the physical trainer.

156 The operational definitions adopted by this study have been widely followed by both football and

157 futsal epidemiological studies (Hägglund, Waldén \& Ekstrand, 2009; Junge \& Dvorak, 2010;

158 Ekstrand et al., 2013; Hamid, Jaafar \& Ali, 2014; Larruskain et al., 2018) and they are displayed

159 in Appendix A1. 
160 Those players who were already injured when the follow up process started (September 2015)

161 were included in this study once medical staff agreed return to training and availability for match

162 selection. Those individuals who were still injured at the end of the study period were included

163 in the statistical analyses, and the estimated duration of the recovery period was established after

164 discussion with the respective medical staff. As a medical history based on information from the

165 player may be confounded by recall bias, previous injuries of those players who were recruited to

166 the team after the study started were not included unless an accurate and detailed description of

167 them were provided in the form of a report or standard form and signed by either a certified

168 medical doctor or a former physiotherapist.

169 Demographic information such as stature, body mass, and age were collected during the last

170 week of the preseason period (which was before the start of the season).

\section{$171 \quad$ 2.3 Data Analysis}

172 Descriptive data are presented as a mean with the corresponding standard deviation (SD),

173 proportions (\%), incidence rates and $95 \%$ confidence intervals (CI). The overall injury incidence,

174 match injury incidence, and training injury incidence were the number of injuries divided by

1751000 player-hours in total, match, and training, respectively. For incidence rates, 95\% CIs were

176 calculated as the incidence \pm 1.96 times the square root of the number of injuries divided by the

177 number of participants. The injury burden was calculated as the number of lay-off days $/ 1000 \mathrm{~h}$.

178 (Bahr, Clarsen \& Ekstrand, 2017) Player overall hours were calculated by adding match and

179 training hours. Player match hours were calculated by multiplying total number of matches in the

180 season per five players per match duration (40 minutes with stopped clock)/60, and player

181 training hours were calculated by adding individual training hours (warm up of the matches was

182 not included). All of the analyses were performed using the PASW statistical package, version 
18318.0 (SPSS Inc., Chicago, IL, USA), with $\mathrm{p}<0.05$ considered statistically significant. A post-

184 hoc power analysis was conducted using the software package, G * Power 3.1.2 (Faul et al.,

185 2007; Erdfelder et al., 2009) The sample size of 39 was used for the statistical power analyses.

186 The alpha level used for this analysis was $\mathrm{p}<0.05$. The post-hoc analyses revealed the statistical

187 power for this study was 0.74 . It could be concluded that the given sample size was large enough

188 to detect significant effects.

189 The spreadsheet designed by Hopkins (2007) for combining effect statistics was used to make

190 clinically (qualitative) inference for paired-comparisons between incidence rates. In particular,

191 the incidence rate ratio (and its associated confidence limits) was assessed against predetermined

192 thresholds. Thus, an incidence rate ratio of 0.91 represented a substantially lower injury risk,

193 while an incidence rate ratio of 1.10 indicated a substantially higher injury risk (Hopkins, 2010).

194 An effect was considered unclear if its confidence interval overlapped the thresholds just

195 mentioned; in other words, if the effect could be substantial in both a positive and negative sense.

196 Otherwise the effect was clear and deemed to have the magnitude of the largest observed

197 likelihood value. The following scale was used to qualify with a probabilistic term the magnitude

198 of the observed effect: $<0.5 \%$, most unlikely; $0.5-5 \%$, very unlikely; 5-25\%, unlikely; $25-75$

$199 \%$, possible; 75-95\%, likely; 95-99.5\%, very likely; >99.5\%, most likely (Hopkins, 2007).

\section{$200 \quad 2.4$ Study quality assessment}

201 The quality of the study was assessed using the "Strengthening the Reporting of Observational

202 Studies in Epidemiology" (STROBE) (von Elm et al., 2014) and the risk of bias of external

203 validity quality, using an adapted version of the Newcastle Ottawa Scale (NOS) (Saragiotto et

204 al., 2014; Videbæk et al., 2015). The study fulfils all the criteria of the STROBE scale except the

205 items 9, 10 and 22 (Appendix A2). Regarding the NOS adapted scale just item 6 was not fulfilled 
206 (Appendix A3). Thus, the reporting and external validity quality of the present study could be

207 considered as high according to the qualitative descriptors proposed by von Elm et al. (2014) and

208 Wells et al. (2013) respectively.

209 3. Results

210 During the three seasons, four players dropped out due to transfers to another club or they were

211 released by the club but their injury data were included based on their time at the club. The

212 average duration of each season was $34.3 \pm 2.1$ weeks with $31 \pm 2.7$ matches per season and 3.3

$213 \pm 1.3$ trainings sessions per week. Player and team characteristics are presented in table 1.

****Table 1 near here ${ }^{* * * *}$

216

217 3.1 Overall, match and training incidence

218 A total of 30 injuries were reported in 15 different players during the three seasons ( 2 match

219 injuries and 28 training injuries) within a total exposure time of $4446.1 \mathrm{~h}(310 \mathrm{~h}$ of match

220 exposure and $4136.1 \mathrm{~h}$ of training exposure), which is equivalent to an overall incidence rate of

2216.75 injuries per 1000 hours of exposure $(95 \% \mathrm{CI}=6.47$ to 7.02$)$. One of the injuries was not

222 taken into account due to the player having to retire from sport because of the injury. The match

223 injury rate was similar (no statistically $[\mathrm{p}>0.05]$ and clinically irrelevant [very likely trivial]

224 differences) to the training injury rate $(6.45,95 \% \mathrm{CI}=6.38$ to 6.52 vs $6.77,95 \% \mathrm{CI}=6.50$ to

$2257.04 / 1000 \mathrm{~h})$ and $38 \%(15 / 39)$ of players sustained at least one injury during the three seasons.

226 Players sustained 0.77 injuries per season on average, which is equivalent to 10 injuries per

227 season for a squad of 13 players. 
228 The injury incidence and characteristics of the injuries during the three seasons are shown in 229 table 2

230

231

${ }^{* * * *}$ Table 2 near here ${ }^{* * * *}$

232

233

\subsection{Injury characteristics}

234

235

236

237

238

239

240

241

242

243

244

245 246 situations.

247

248

\subsubsection{Player position}

Lastwomen $(3.37,95 \% \mathrm{CI}=2.74$ to $4.01 / 1000 \mathrm{~h})$ incidence rate was most likely higher $(100 \%$ likelihood) than wings $(2.02,95 \% \mathrm{CI}=1.57$ to $2.48 / 1000 \mathrm{~h})$, goalkeepers $(0.90,95 \% \mathrm{CI}=0.34$

to $1.46 / 1000 \mathrm{~h})$ and pivots $(0.45,95 \% \mathrm{CI}=0.05$ to $0.85 / 1000 \mathrm{~h})$. Wings had a very likely higher incidence rate (96.6\% likelihood) than goalkeepers and most likely higher $(100 \%$ likelihood) than pivots. Finally, goalkeepers had a likely higher incidence rate (76.6\% likelihood) than pivots.

\subsubsection{Injury mechanism}

Two out of three injuries were due to trauma and one out of three injuries was due to overuse.

The incidence rate of traumatic injuries was most likely higher (100\% likelihood) than overuse injuries $(4.5,95 \% \mathrm{CI}=4.27$ to 4.72 vs $2.25,95 \% \mathrm{CI}=2.09$ to $2.41 / 1000 \mathrm{~h})$. Most injuries were caused by non-contact situations ( $93 \%$ ), with only $7 \%$ of injuries occurring during contact

\subsubsection{Injury location}

Table 3 shows the injury location and type of injury per season. Lower extremity injuries (5.62 per 1000 hours of exposure, $95 \% \mathrm{CI}=5.37$ to 5.87 ) were the most frequently injured location, followed by upper limb injuries ( 0.67 per 1000 hours of exposure, $95 \% \mathrm{CI}=0.59$ to 0.76$)$, and 
251 then trunk injuries $(0.45$ per 1000 hours of exposure, $95 \% \mathrm{CI}=0.38$ to 0.52$)$. No head and neck

252 injuries were reported. The lower extremity region predominantly injured was the thigh (3.37 per

2531000 hours of exposure, $95 \% \mathrm{CI}=3.18$ to 3.57 ), followed by the ankle ( 0.90 per 1000 hours of

254 exposure, $95 \% \mathrm{CI}=0.8$ to 1.0 ), with the knee, hip/groin and lower leg/Achilles tendon regions

255 demonstrating the same incidence rate $(0.45$ per 1000 hours of exposure, $95 \% \mathrm{CI}=0.38$ to 0.52$)$.

256 No foot/toe injuries were reported. In terms of paired-comparisons, thigh injuries occurred more

257 frequently (100\% likelihood) than injuries in other lower extremity regions. Ankle injury rates

258 were most likely higher (100\% likelihood) than knee, hip/groin and lower leg/Achilles tendon

259 injuries. There were no meaningful differences between the remaining paired combinations.

\subsubsection{Type of injuries}

264 The mean incidence of injury type grouping is presented per 1000 hours of exposure with $95 \%$

265 CIs. Most injuries were diagnosed as muscle/tendon injuries (4.95, 4.71 to 5.18), followed by 266 joint (non-bone) and ligament $(1.35,1.23$ to 1.47$)$, and fractures and bone stress and contusions

267 with the same injury incidence $(0.22,0.17$ to 0.28$)$. No central/peripheral nervous system injuries 268 and skin lesions were recorded. The most common injury types were hamstring muscle injuries 269 (1.80 per 1000 hours of exposure, $95 \% \mathrm{CI}=0.66$ to 1.94$)$, followed by quadriceps muscle 270 injuries ( 1.57 per 1000 hours of exposure, $95 \% \mathrm{CI}=1.44$ to 1.71 ), ankle sprains ( 0.90 per 1000

271 hours of exposure, $95 \% \mathrm{CI}=0.8$ to 1.0$)$ and anterior cruciate ligament tears $(0.45$ per 1000 hours

272 of exposure, $95 \% \mathrm{CI}=0.38$ to 0.52 ). Muscle/tendon injury incidence rates were most likely

273 higher than other types of injury rates (100\% likelihood). Likewise, joint (non-bone) and 
274 ligament incidence rate were most likely higher (100\% likelihood) than fractures, bone stress and 275 contusions.

\section{$276 \quad 3.2 .5$ Severity of injuries}

277 Concerning the severity of injuries, moderate injuries (2.70 per 1000 hours of exposure, $95 \%$ CI

$278=2.52$ to 2.87$)$ were the most usual injuries, followed by minimal and mild injuries $(1.80$ per

2791000 hours of exposure, $95 \% \mathrm{CI}=1.66$ to 1.94 ), and finally severe and career ending injuries

280 (0.22 per 1000 hours of exposure, $95 \% \mathrm{CI}=0.17$ to 0.28$)$. No 0 days injuries were recorded.

281 Comparisons between each severity level showed that the moderate injury incidence rates were

282 most likely higher (100\% likelihood) than other severities. Minimal and mild injury incidence

283 rates were most likely higher (100\% likelihood) than severe and career ending injuries.

284 The recorded overall time-loss injuries was 429 days, so overall injury burden during the three

285 seasons was 96.5 days loss/1000 hours exposure (58.1 in matches and 99.4 in trainings). Figure 1

286 shows a quantitative risk matrix illustrating the relationship between the severity and incidence

287 of the most common reported injuries For each injury type, severity is shown as the average

288 number of days lost (log scale), while incidence is shown as the number of injuries per 1000

289 hours of total exposure for each injury type. The shading illustrates relative importance of each

290 of the injury types; the darker the colour, the greater the injury burden, and the greater the

291 priority should be given to prevention. Furthermore, lastwomen and pivots showed the highest

292 injury burden (40.9 and 33.3 days loss/1000 hours exposure) compared to goalkeepers and wings

293 (7.9 and 14.4 days loss/1000 hours exposure). On the other hand, muscle/tendon injuries and

294 joint (non-bone) and ligament injuries showed similar injury burden (44.98 and 49.48 days

295 loss/1000 hours exposure) although their overall incidence was significantly different. Regarding

296 injury location, the knee showed a significantly higher injury burden (31.9 days loss/1000 hours 
297 exposure) compared to the rest of the lower extremity muscle groups (ankle: 17.5; quadriceps:

298 15.3; hamstring: 14.4; hip/groin: 5.8 and lower leg/Achilles tendon: 4.0).

299

300

${ }^{* * * *}$ Figure 1 near here ${ }^{* * * *}$

301

302

$303 \quad$ 3.2.6 Recurrent injuries

304 The incidence rate of new injuries (5.62 per 1000 hours of exposure, $95 \% \mathrm{CI}=5.37$ to 5.87 ) was

305 most likely higher (100\% likelihood) than recurrent injuries incidence rate (1.12 per 1000 hours

306 of exposure, $95 \% \mathrm{CI}=1.01$ to 1.24 ). One-fifth of the overall injuries were recurrent injuries; of

307 these, $20 \%$ of injuries were classified as "early recurrence" (within $0-2$ months); $60 \%$ of injuries

308 were classified as "late recurrence" (2-12 months); and 20\% of injuries were classified as

309 "delayed recurrence" (>12 months) (Fuller et al., 2007). The most common recurrent injury was

310 quadriceps and hamstring strains. Regarding injury burden, new injuries had a significantly

311 higher injury burden compared to recurrent injuries ( 86.4 vs 1.1 days lost/1000 hours exposure).

$312 \quad 3.2 .7$ Season variation of injury pattern

313 Figure 2 illustrates monthly distribution of injuries, both overall, during training and match over

314 the three seasons. The highest incidence of injuries was observed in October (1.35 per 1000

315 hours of exposure, $95 \% \mathrm{CI}=1.23$ to 1.47 ). Training and match number of injuries follow a

316 similar trend, in which the risk of injuries was higher in the early stages of the season and post

317 winter/Christmas break.

318

319

${ }^{* * * *}$ Figure 2 near here ${ }^{* * * *}$ 


\section{Discussion}

322 The overall, training and match incidence rates reported in the current study were comparable to

323 those found in the only study (to the authors' knowledge) that has provided three incidence rates

324 separately in a cohort of 17 female futsal players (Angoorani et al., 2014) (4.7, 3.1 and 10.7

325 injuries per $1000 \mathrm{~h}$ of exposure to overall, training and match play, respectively). Conversely, the

326 match injury incidence reported in the current study (6.4 injuries per $1000 \mathrm{~h}$ of match play) is

327 lower than that reported by Hamid et al. (Hamid, Jaafar \& Ali, 2014) in the Malaysian female

328 futsal league (29.6 injuries per $1000 \mathrm{~h}$ of exposure to match play). An explanation of this

329 discrepancy may be attributed to the more congested competitive calendar in the study carried

330 out by Hamid et al. (Hamid, Jaafar \& Ali, 2014) compared to our study. Thus, while in their

331 study the Malaysian league had a duration of approximately 22 weeks $\left(1^{\text {st }} \mathrm{July}\right.$ until $28^{\text {th }}$

332 November) with a break in August (because of fasting during Ramadan) and one or two matches

333 per week, the three seasons (2015-2018) of the Spanish second division analyzed in the current

334 study lasted eight months (average of $34.3 \pm 2.1$ weeks) with two breaks periods of 2-3 weeks (at

335 Christmas and Easter) with one match played per week (usually at the weekend days). This

336 hypothesis may be supported by evidence from prospective epidemiological studies carried out

337 in elite male futsal players (Ribeiro, Oliveira \& Costa, 2006; Junge \& Dvorak, 2010) and football

338 players (Dvorak et al., 2011; Junge \& Dvořák, 2015) during international tournaments (i.e.

339 World cups) which have shown higher incidence rates in comparison with those conducted

340 during national league futsal (Hamid, Jaafar \& Ali, 2014; Álvarez Medina et al., 2016) and

341 football (Noya Salces et al., 2014; Stubbe et al., 2015). This is likely due to the higher match

342 demands during international tournaments with relatively shorter recovery times between 
343 matches. These tournaments also tend to occur at the end of long competitive league seasons

344 where accumulated fatigue may also be a factor in the higher incidence rates.

345 Unlike data from other team sports (regardless of the sex of the players) [i.e. football, (Giza et

346 al., 2005; Waldén, Hägglund \& Ekstrand, 2007) basketball (Borowski et al., 2008), netball

347 (Best, 2017)] where match injury incidence is always notably higher (almost ten times) than the

348 injury rate obtained for training sessions, in our study both incidence rates were similar. The

349 latest trends in strength and conditioning for team sports have suggested that training session

350 design (i.e. work-load, intensity, duration), when possible, should mimic match demands so that

351 players are better prepared for what they face during matches (Gabbett, 2016). Perhaps, the

352 training sessions designed by the team staff might have included a large number of repeated

353 high-intensity actions (e.g. accelerations and decelerations, changes of direction) in order to

354 replicate the evolving nature of the futsal game. However, an excessive training load and/or an

355 insufficient recovery of previous efforts might have forced players to perform some of these

356 highly demanding training sessions under suboptimal states of readiness and this could have

357 potentially increased the risk of injuries (mainly muscle-tendon and ligament injuries) (Gabbett,

358 2004). To determine whether or not futsal players are in an optimal state of readiness for the

359 stress that will be a priori elicited by training, it is advisable to monitor daily training load

360 (internal and external) and strain, wellbeing and recovery status from previous efforts and also

361 include regular physical performance tests as a component of the training program (Bouaziz et

362 al., 2016; Elloumi, Makni, Moalla, Bouaziz, Tabka, Lac, Chamari, 2012). This information

363 might help coaches and physical trainers to constantly re-adjust the design of the training

364 sessions throughout the season so that the physical and psychological demands that will be

365 imposed on the players do not negatively affect their optimal readiness to re-perform. 
366 When exploring differences in playing position on incidence rates our data from the goalkeepers

367 and outfield player's differed from the findings previously reported by Hamid et al. (2014) Their

368 study, also in female futsal players, showed a higher incidence rate in goalkeepers but we found

369 outfield players showed higher incidence and higher amount of days off per injury than

370 goalkeepers. Our findings are similar to that which has been reported in other team sports such as

371 handball (Tsigilis \& Hatzimanouil, 2005) and football (Mallo et al., 2011; Falese, Della Valle \&

372 Federico, 2016). It is difficult to prescribe a reason for the discrepancy between the findings of

373 Hamid et al. (Hamid, Jaafar \& Ali, 2014) and our current study. However, it might be due to the

374 fact that outfield players need to perform a larger number of repeated high intensity multiplanar

375 movements that occur every few seconds (Dogramaci \& Watsford, 2006), which may place

376 outfield players at a higher risk of injury than goalkeepers.

377 Previous studies have indicated that a large percentage of injuries in male futsal players (Ribeiro,

378 Oliveira \& Costa, 2006; Junge \& Dvorak, 2010) are caused by contact trauma, however the

379 current study demonstrates that most injuries sustained by female players are due to non-contact

380 trauma (>90\%). Our results are in agreement with the study of Angoorani's et al. (2014) and

381 might be partly attributed to the fact that both studies included training injury incidence data,

382 something that other studies have failed to do. Furthermore, the higher number of high intensity

383 phases observed in elite male players during the course of futsal play (Carling et al., 2015;

384 Naser, Ali \& Macadam, 2017) might contribute to generate more tackling situations and partially

385 explain the fact that males suffer more contact injuries than females.

386 With respect to the location of futsal-related injuries, and similar to previous studies in male

387 (Ribeiro, Oliveira \& Costa, 2006; Junge \& Dvorak, 2010; Álvarez Medina et al., 2016) and

388 female futsal players (Angoorani et al., 2014; Hamid, Jaafar \& Ali, 2014), lower extremity 
389 injuries were, by far, the most frequent injuries ( $83.3 \%$ of all the injuries recorded). The thigh

$390(50 \%$ of all the injuries recorded) was the anatomical region of the lower extremity where

391 injuries occurred significantly more followed by the knee ( $6.7 \%$ of all the injuries recorded) and

392 ankle (6.7\% of all the injuries recorded). Furthermore, the most common type of injury grouping

393 was muscle/tendon injuries followed by joint (non-bone) and ligament injuries. As futsal is a

394 fast-paced game relying mostly on the lower extremity for ball control, involving sprinting and

395 frequent changes in direction such observations were anticipated. In football, it has been

396 demonstrated that player match availability has a strong correlation $(r>0.85)$ with team success

397 (i.e. ranking position, games won, goals scored, total points) (Eirale et al., 2013; Hägglund et al.,

398 2013; Carling et al., 2015). If this statement also holds for futsal, then injury prevention

399 measures should focus not just on reduction of the incidence of the most frequent injuries but

400 also on reduction of the injuries with the highest burden (e.g. those injuries that keep players out

401 of training and match play the longest) (Bahr, Clarsen \& Ekstrand, 2017). According to the

402 results found in this study, knee and thigh injuries are those with the highest injury burden with

40331.9 and 29.7 days of absence per 1000 player hours, respectively. In particular, medical and

404 fitness staff should implement measures mainly aimed (but not solely) at reducing the number

405 and severity of anterior cruciate ligament (ACL) and hamstring and quadriceps muscle injuries.

406 It should be noted that one player from the team had to retire from futsal due to an ACL rupture,

407 which was not included in the injury burden calculation as the number of days lost were not

408 defined. This reinforces the need to deliver targeted interventions aimed at reducing this

409 devasting and relatively frequent (two cases in the three seasons recorded in our study for a

410 single team) type of injury in female athletes. It should be also highlighted that the overall (31.7

411 days) and training (30 days) injury burdens of the last season analyzed (2017/18) were 
412 significantly lower than those obtained for the two previous seasons (overall $=155.3[2015 / 16]$

413 and 108.4 [2016/17] days; training $=165.6[2015 / 16]$ and 108.0 [2016/17] days). Perhaps, the

414 fact that during the three seasons that were object of study the club kept the same medical staff

415 and head coach may have been a factor that may explain in part this circumstance. In this sense,

416 and similar to what was found in previous studies (Ekstrand et al., 2018; Lausic et al., 2009), the

417 potential and gradual improvement in the quality of the internal communication not only within

418 the members of the medical staff but also between the medical staff and the coach that might

419 have occurred throughout the three consecutive seasons may have had a positive impact on the

420 players' availability for futsal play in the last season. In fact, according to Ekstrand, et al. (2018),

421 the measures designed to reduce the injury burden in elite teams should not only address the

422 traditionally proposed modifiable injury risk factors [e.g. eccentric strength deficits (Croisier et

423 al., 2008; Petersen et al., 2011; van Dyk et al., 2016), poor neuromuscular control (Lees \&

424 Nolan, 1998; Hewett et al., 2005), altered muscle architecture (Lees \& Nolan, 1998; Arnason et

425 al., 2004; Timmins et al., 2016), player load and match frequency (Rahnama et al., 2003;

426 Miloski, Freitas \& Barra-Filho, 2012) but also some new external factors such as job security

427 and club stability and players adherence and coaches compliance to the injury prevention

428 programs applied. The inclusion of updated and evidence-based advancements in factors related

429 to injury management (including diagnosis techniques, treatment approaches and monitoring

430 tools) might also have a positive impact on the injury burden.

431 As expected, new injury rates were higher than recurrent injury incidence rates (5.6 vs. 1.1

432 injuries per $1000 \mathrm{~h}$ ). However, the recurrent rate identified in the present study may be

433 considered high. It was found that $20 \%$ of recurrent injuries (mainly lower extremity muscle and

434 tendon injuries) occurred within 2 months after return to play. This may be regarded as a sign of 
435 premature return to train/play and incomplete or inadequate rehabilitation. The lack of and 436 evidence-based criteria for a safe return to train/play may have resulted in letting injured players

437 return to play sooner than recommended. This may have been due to the desire to let them play

438 in important matches or to let them play with ongoing minor symptoms, and this might be two

439 primary reasons behind the high recurrent injury incidence rate. Future studies should extend our

440 current knowledge further in relation to the improvement of the decision-making process for a

441 safe return to train/play by developing learning algorithms or artificial intelligence-based models

442 that allow the identification of when a player is successfully rehabilitated before returning to

443 train/play. Furthermore, medical and fitness team staff should allow players enough time for

444 rehabilitation before return to train/play.

445 Regarding the moment when most injuries took place, the findings indicates that there are two 446 periods when they are more likely to occur, October and January-February. The higher amount

447 of injuries during October may be explained by the fact that within the pre-season period the

448 training loads are much higher than during the competitive period (Miloski, Freitas \& Barra-

449 Filho, 2012) and accumulating fatigue may increase the injury risk during the first weeks of

450 competition. Petersen et al. (2010). reported a higher incidence in the two months after the winter

451 break (January-February) which is consistent with the results of the present study.

\section{4.1 Limitations}

453 Despite being one of the first prospective studies that has analysed the incidence rates and 454 characteristics of futsal related injuries in female players, some limitations must be considered.

455 The sample size of players and injuries is small, and results should be cautiously interpreted 456 (especially the incidence rates reported for specific and less frequent injuries). The analysis of

457 only one team limits the external validity of the results. Consequently, it is unknown if female 
458 players from other teams in which there could be a higher (or lower) medical staff-to-player ratio

459 or access to other staff (such as strength and conditioning coaches, psychologists and

460 nutritionists) may show similar injury incidence rates and characteristics than those reported in

461 the current study. Even though all female players had sub-elite status, most of them had jobs

462 besides futsal that could alter their risk of injury and recovery time, for example, by preventing

463 them from training or taking full advantage of medical treatment. Therefore, future studies are

464 needed in order to analyze if elite female futsal players on full-time (professional) contracts may

465 show different injury incidence rates, characteristics and burden.

466

\section{Conclusions}

467 Sub-elite female futsal players (particularly outfield players) are exposed to a substantial risk of 468 sustaining injuries. Most injuries had a non-contact mechanism, with the lower extremity the 469 most frequently injured anatomical region. Knee (anterior cruciate ligament tears) and thigh 470 (hamstring and quadriceps muscle strains) injuries are those with the highest injury burden.

471 Special attention should be given to the first weeks of competition after pre-season and soon 472 after the Christmas break as incidence rates peak during this period in female futsal players.

473 Medical and fitness team staff should focus their attention on designing, implementing and then 474 evaluating preventative measures that target the most common diagnoses, namely, ligament and 475 muscle/tendon injuries highlighted in this study, as well as making sure that return to train/play 476 criteria are in place in order to reduce the injury burden within female sub-elite futsal players. 477

\section{Acknowledgments}

479 Iñaki Ruiz-Pérez were supported by predoctoral grant given by Ministerio de Economía y 480 Competitividad (FPI BES-2015-07200) from Spain. Francisco Ayala were supported by 
481 postdoctoral grant given by Seneca Foundation (postdoctoral fellowships funded by the regional 482 sub program focuses on the postdoctoral development, 20366/PD/17) from Spain.

483

\section{Competing interest}

485 None declared

486 Funding

487 None declared

488 


\section{References}

491 Almeida SA, Williams KM, Shaffer RA, Brodine SK. 1999. Epidemiological patterns of

492 musculoskeletal injuries and physical training. Medicine and Science in Sports and Exercise $493 \quad 31: 1176-82$.

494 Álvarez Medina J, Murillo Lorente V, Giménez Salillas L, Manonelles Marqueta P. 2016.

495 Modificación del volumen-intensidad como medida preventiva de lesiones en fútbol sala.

496 Revista Internacional de Medicina y Ciencias de la Actividad Fisica y del Deporte 16:85-

497 97. DOI: $10.15366 /$ rimcafd2016.61.007.

498 Angoorani H, Haratian Z, Mazaherinezhad A, Younespour S. 2014. Injuries in Iran futsal

499 national teams: A comparative study of incidence and characteristics. Asian Journal of

$500 \quad$ Sports Medicine 5:0-4. DOI: 10.5812/asjsm.23070.

501 Arnason A, Sigurdsson SB, Gudmundsson A, Holme I, Engebretsen L, Bahr R. 2004. Risk

502 Factors for Injuries in Football. American Journal of Sports Medicine 32:5-16. DOI:

$503 \quad 10.1177 / 0363546503258912$.

504 Asker M, Holm LW, Källberg H, Waldén M, Skillgate E. 2018. Female adolescent elite handball

505 players are more susceptible to shoulder problems than their male counterparts. Knee

506 Surgery, Sports Traumatology, Arthroscopy 26:1892-1900. DOI: 10.1007/s00167-018-

$507 \quad 4857-y$.

508 Bahr R, Clarsen B, Ekstrand J. 2017. Why we should focus on the burden of injuries and

$509 \quad$ illnesses, not just their incidence. British Journal of Sports Medicine 0:bjsports-2017-

510 098160. DOI: 10.1136/bjsports-2017-098160.

511 Beato M, Coratella G, Schena F. 2016. Brief review of the state of art in futsal. Journal of Sports

$512 \quad$ Medicine and Physical Fitness 56:428-32. 
513 Beato M, Coratella G, Schena F, Hulton AT. 2017. Evaluation of the external \& internal

514 workload in female futsal players. Biology of Sport 34:227-231. DOI:

$515 \quad 10.5114 /$ biolsport.2017.65998.

516 Best G. 2017. Epidemiology and Incidence of Injury in Elite Netball Players - an Injury Audit of

517 the 2016 Netball Superleague Season. British Journal of Sports Medicine 51:297.1-297.

518 DOI: $10.1136 /$ bjsports-2016-097372.34.

519 Borowski LA, Yard EE, Fields SK, Comstock RD. 2008. The Epidemiology of US High School

520 Basketball Injuries, 2005-2007. American Journal of Sports Medicine 36:2328-2335. DOI:

$521 \quad 10.1177 / 0363546508322893$.

522 Brooks JHM, Fuller CW, Kemp SPT, Reddin DB. 2008. An assessment of training volume in

523 professional rugby union and its impact on the incidence, severity, and nature of match and

524 training injuries. Journal of Sports Sciences 26:863-873. DOI:

$525 \quad 10.1080 / 02640410701832209$.

526 Carling C, Le Gall F, McCall A, Nédélec M, Dupont G. 2015. Squad management, injury and

527 match performance in a professional soccer team over a championship-winning season.

$528 \quad$ European Journal of Sport Science 15:573-582. DOI: 10.1080/17461391.2014.955885.

529 Castagna C, D’Ottavio S, Vera JG, Álvarez JCB. 2009. Match demands of professional Futsal: A $530 \quad$ case study. Journal of Science and Medicine in Sport 12:490-494. DOI:

531 10.1016/j.jsams.2008.02.001.

532 Croisier J-L, Ganteaume S, Binet J, Genty M, Ferret J-M. 2008. Strength Imbalances and

533 Prevention of Hamstring Injury in Professional Soccer Players. American Journal of Sports 534 Medicine 36:1469-1475. DOI: 10.1177/0363546508316764.

535 Dogramaci SN, Watsford ML. 2006. A comparison of two different methods for time-motion 
analysis in team sports. International Journal of Performance Analysis in Sport 6:73-83. DOI: $10.1017 / \mathrm{CBO} 9781107415324.004$.

Dvorak J, Junge A, Derman W, Schwellnus M. 2011. Injuries and illnesses of football players during the 2010 FIFA World Cup. British Journal of Sports Medicine 45:626-630. DOI: 10.1136/bjsm.2010.079905.

van Dyk N, Bahr R, Whiteley R, Tol JL, Kumar BD, Hamilton B, Farooq A, Witvrouw E. 2016. Hamstring and Quadriceps Isokinetic Strength Deficits Are Weak Risk Factors for Hamstring Strain Injuries. American Journal of Sports Medicine 44:1789-1795. DOI:

Ekstrand J, Hägglund M, Kristenson K, Magnusson H, Waldén M. 2013. Fewer ligament injuries

Eirale C, Tol JL, Farooq A, Smiley F, Chalabi H. 2013. Low injury rate strongly correlates with $10.1177 / 0363546516632526$. but no preventive effect on muscle injuries and severe injuries: an 11-year follow-up of the UEFA Champions League injury study. British Journal of Sports Medicine 47:732-737. DOI: 10.1136/bjsports-2013-092394.

Ekstrand J, Lundqvist D, Davison M, D’Hooghe M, Pensgaard AM. 2018. Communication quality between the medical team and the head coach/manager is associated with injury

Erdfelder E, Faul F, Buchner A, Lang AG. 2009. Statistical power analyses using G*Power 3.1: burden and player availability in elite football clubs. British Journal of Sports Tests for correlation and regression analyses. Behavior Research Methods 41:1149-1160. DOI: 10.3758/BRM.41.4.1149. 
559 Falese L, Della Valle P, Federico B. 2016. Epidemiology of football (soccer) injuries in the

$5602012 / 2013$ and 2013/2014 seasons of the Italian Serie A. Research in Sports Medicine

$56124: 426-432$. DOI: $10.1080 / 15438627.2016 .1239105$.

562 Faul F, Erdfelder E, Lang A-G, Buchner A. 2007. G*Power 3: a flexible statistical power

563 analysis program for the social, behavioral, and biomedical sciences. Behavior Research

$564 \quad$ Methods 39:175-91.

565 FIFA C. 2007. FIFA Big Count 2006: 270 million people active in football. FIFA

566 Communications Division, Information Services 31:1-12.

567 Finch C. 2006. A new framework for research leading to sports injury prevention. Journal of

$568 \quad$ Science and Medicine in Sport 9:3-9. DOI: 10.1016/j.jsams.2006.02.009.

569 Fuller CW. 2018. Injury Risk (Burden), Risk Matrices and Risk Contours in Team Sports: A

570 Review of Principles, Practices and Problems. Sports Medicine 48:1597-1606. DOI:

$571 \quad 10.1007 / \mathrm{s} 40279-018-0913-5$.

572 Fuller CW, Ekstrand J, Junge A, Andersen TE, Bahr R, Dvorak J, Hägglund M, McCrory P,

573 Meeuwisse WH. 2006. Consensus statement on injury definitions and data collection

574 procedures in studies of football (soccer) injuries. Clinical Journal of Sport

$575 \quad$ Medicine 16:97-106.

576 Gabbett TJ. 2004. Influence of training and match intensity on injuries in rugby league. Journal

577 of Sports Sciences 22:409-417. DOI: 10.1080/02640410310001641638.

578 Gabbett TJ. 2016. The training-injury prevention paradox: Should athletes be training smarter

579 and harder? British Journal of Sports Medicine 50:273-280. DOI: 10.1136/bjsports-2015-

$580 \quad 095788$.

581 Giza E, Mithöfer K, Farrell L, Zarins B, Gill T, Drawer S. 2005. Injuries in women's 
professional soccer. British Journal of Sports Medicine 39:212-216. DOI: 10.1136/bjsm.2004.011973.

584 Gorostiaga EM, Llodio I, Ibáñez J, Granados C, Navarro I, Ruesta M, Bonnabau H, Izquierdo M. 585 2009. Differences in physical fitness among indoor and outdoor elite male soccer players. European Journal of Applied Physiology 106:483-491. DOI: 10.1007/s00421-009-1040-7.

Hägglund M, Waldén M, Bahr R. 2005. Methods for epidemiological study of injuries to professional football players: developing the UEFA model. British Journal of Sports Medicine 39:340-346. DOI: 10.1136/bjsm.2005.018267.

Hägglund M, Waldén M, Ekstrand J. 2009. Injuries among male and female elite football players. Scandinavian Journal of Medicine and Science in Sports 19:819-827. DOI: affect team performance negatively in professional football: An 11-year follow-up of the UEFA Champions League injury study. British Journal of Sports Medicine 47:738-742. DOI: 10.1136/bjsports-2013-092215.

Hamid MSA, Jaafar Z, Ali ASM. 2014. Incidence and characteristics of injuries during the 2010 FELDA/FAM national futsal league in Malaysia. PLoS ONE 9:2-7. DOI: 10.1371/journal.pone.0095158.

Hewett TE, Myer GD, Ford KR, Heidt RS, Colosimo AJ, McLean SG, van den Bogert AJ, Paterno M V., Succop P. 2005. Biomechanical Measures of Neuromuscular Control and Valgus Loading of the Knee Predict Anterior Cruciate Ligament Injury Risk in Female Athletes: A Prospective Study. American Journal of Sports Medicine 33:492-501. DOI: $10.1177 / 0363546504269591$. 
605 Hopkins W. 2007. A spreadsheet for deriving a confidence interval, mechanistic inference and 606 clinical inference from a p value. Sportscience 11:16-20. DOI: NOT FOUND.

607 Hopkins W. 2010. Linear Models and Effect Magnitudes for Research, Clinical, and Practical $608 \quad$ Applications. Sportscience 14:49-57.

609 Junge A, Dvorak J. 2010. Injury risk of playing football in Futsal World Cups. British Journal of $610 \quad$ Sports Medicine 44:1089-1092. DOI: 10.1136/bjsm.2010.076752.

611 Junge A, Dvořák J. 2015. Football injuries during the 2014 FIFA World Cup. British Journal of 612 Sports Medicine 49:599-602. DOI: 10.1136/bjsports-2014-094469.

613 Larruskain J, Lekue JA, Diaz N, Odriozola A, Gil SM. 2018. A comparison of injuries in elite 614 male and female football players: A five-season prospective study. Scandinavian Journal of 615 Medicine \& Science in Sports 28:237-245. DOI: 10.1111/sms.12860.

616 Lees A, Nolan L. 1998. The biomechanics of soccer: A review. Journal of Sports Sciences $617 \quad$ 16:211-234. DOI: 10.1080/026404198366740.

618 Lausic D, Tennebaum G, Eccles D, Jeong A, Johnson T. 2009. Intrateam communication and 619 performance in doubles tennis. Research Quarterly for Exercise and Sport. 80: 281-290.

$620 \quad$ DOI: $\underline{10.1080 / 02701367.2009 .10599563}$

621 Mallo J, González P, Veiga S, Navarro E. 2011. Injury incidence in a spanish sub-elite 622 professional football team: A prospective study during four consecutive seasons. Journal of $623 \quad$ Sports Science and Medicine 10:731-736.

624 van Mechelen W, Hlobil H, Kemper HCG. 1992. Incidence, Severity, Aetiology and Prevention 625 of Sports Injuries: A Review of Concepts. Sports Medicine: An International Journal of 626 Applied Medicine and Science in Sport and Exercise 14:82-99. DOI: 10.2165/00007256$627 \quad 199214020-00002$. 
628 Miloski B, Freitas VH, Barra-Filho MG. 2012. Monitoring of the internal training load in futsal

629 players over a season. Brazilian Journal of Kinanthropometry and Human Performance

630 14:671-679. DOI: 10.5007/1980-0037.2012v14n6p671.

631 Naser N, Ali A, Macadam P. 2017. Physical and physiological demands of futsal. Journal of

632 Exercise Science \& Fitness 15:76-80. DOI: 10.1016/j.jesf.2017.09.001.

633 Noya Salces J, Gomez-Carmona PM, Moliner-Urdiales D, Gracia-Marco L, Sillero-Quintana M.

634 2014. An examination of injuries in Spanish Professional Soccer League. Journal of Sports

635 Medicine and Physical Fitness 54:765-771. DOI: 10.1007/s11816-009-0104-9.

636 Peck KY, Johnston DA, Owens BD, Cameron KL. 2013. The Incidence of Injury Among Male

637 and Female Intercollegiate Rugby Players. Sports Health 5:327-333. DOI:

$638 \quad 10.1177 / 1941738113487165$.

639 Petersen J, Thorborg K, Nielsen MB, Budtz-Jørgensen E, Hölmich P. 2011. Preventive Effect of

640 Eccentric Training on Acute Hamstring Injuries in Men’s Soccer. American Journal of

$641 \quad$ Sports Medicine 39:2296-2303. DOI: 10.1177/0363546511419277.

642 Petersen J, Thorborg K, Nielsen MB, Hölmich P. 2010. Acute hamstring injuries in Danish elite

643 football: A 12-month prospective registration study among 374 players. Scandinavian

644 Journal of Medicine and Science in Sports 20:588-592. DOI: 10.1111/j.1600-

$645 \quad$ 0838.2009.00995.x.

646 Rahnama N, Reilly T, Lees A, Graham-Smith P. 2003. Muscle fatigue induced by exercise

647 simulating the work rate of competitive soccer. Journal of Sports Sciences 21:933-942.

648 DOI: $10.1080 / 0264041031000140428$.

649 Ribeiro RN, Oliveira L, Costa P. 2006. Epidemiologic analysis of injuries occurred during the 15

650 th Brazilian Indoor Soccer ( Futsal ) Sub20 Team Selection Championship. Revista 
Brasileira De Medicina 12:9-12.

652 Saragiotto BT, Yamato TP, Hespanhol Junior LC, Rainbow MJ, Davis IS, Lopes AD. 2014.

653 What are the Main Risk Factors for Running-Related Injuries? Sports Medicine 44:1153-

654 1163. DOI: $10.1007 / \mathrm{s} 40279-014-0194-6$.

655 Stubbe JH, van Beijsterveldt A-MMC, van der Knaap S, Stege J, Verhagen EA, van Mechelen 656 W, Backx FJG. 2015. Injuries in Professional Male Soccer Players in the Netherlands: A 657 Prospective Cohort Study. Journal of Athletic Training 50:211-216. DOI: 10.4085/1062$658 \quad 6050-49.3 .64$

659 Van Tiggelen D, Wickes S, Stevens V, Roosen P, Witvrouw E. 2008. Effective prevention of 660 sports injuries: A model integrating efficacy, efficiency, compliance and risk-taking 661 behaviour. British Journal of Sports Medicine 42:648-652. DOI:

662 10.1136/bjsm.2008.046441.

663 Timmins RG, Bourne MN, Shield AJ, Williams MD, Lorenzen C, Opar DA. 2016. Short biceps 664 femoris fascicles and eccentric knee flexor weakness increase the risk of hamstring injury in 665 elite football (soccer): a prospective cohort study. British Journal of Sports Medicine 666 50:1524-1535. DOI: 10.1136/bjsports-2015-095362.

667 Tsigilis N, Hatzimanouil D. 2005. Injuries in handball: Examination of the risk factors. $668 \quad$ European Journal of Sport Science 5:137-142. DOI: 10.1080/17461390500221610. 669 Videbæk S, Bueno AM, Nielsen RO, Rasmussen S. 2015. Incidence of Running-Related Injuries 670 Per $1000 \mathrm{~h}$ of running in Different Types of Runners: A Systematic Review and Meta671 Analysis. Sports Medicine 45:1017-1026. DOI: 10.1007/s40279-015-0333-8.

672 von Elm E, Altman DG, Egger M, Pocock SJ, Gøtzsche PC, Vandenbroucke JP. 2014. The 673 strengthening the reporting of observational studies in epidemiology (STROBE) statement: 
674 Guidelines for reporting observational studies. International Journal of Surgery 12:1495675 1499. DOI: 10.1016/j.ijsu.2014.07.013.

676 Waldén M, Hägglund M, Ekstrand J. 2007. Football injuries during European Championships

677 2004-2005. Knee Surgery, Sports Traumatology, Arthroscopy 15:1155-1162. DOI:

$678 \quad 10.1007 / \mathrm{s} 00167-007-0290-3$.

679 Wells G, B Shea, O’Connell D, Peterson J, Welch V, Losos M, Tugwell P. 2013.The Newcastle680 Ottawa Scale (NOS) for assessing the quality of nonrandomised studies in meta-analyses.

681 Available at http://www.ohri.ca/programs/clinical_epidemiology/oxford.asp (accessed

$682 \quad$ November 15, 2018). DOI: 10.1006/anae.1997.0142.

683 


\section{Figures legend}

686 Figure 1. Quantitative risk matrix of injuries, illustrating the relationship between the severity

687 (consequence) and incidence (likelihood) of the most common injuries.

688 Figure 2. Distribution of total injury incidence.

689

690

\section{Appendices legend}

692 Appendix A1. Definitions used in the study. Injury definitions.

693 Appendix A2. Description of the 22 of STROBE Statement — checklist of items that should be included in 694 reports of observational studies.

695 Appendix A3: Description of the 8 criteria designed to assess risk of bias of external validity quality in the 696 studies. This instrument is an adapted version of the Newcastle Ottawa Scale (NOS) for cohort studies.

697

698 


\section{Figure 1}

Quantitative risk matrix of injuries, illustrating the relationship between the severity (consequence) and incidence (likelihood) of the most common injuries.

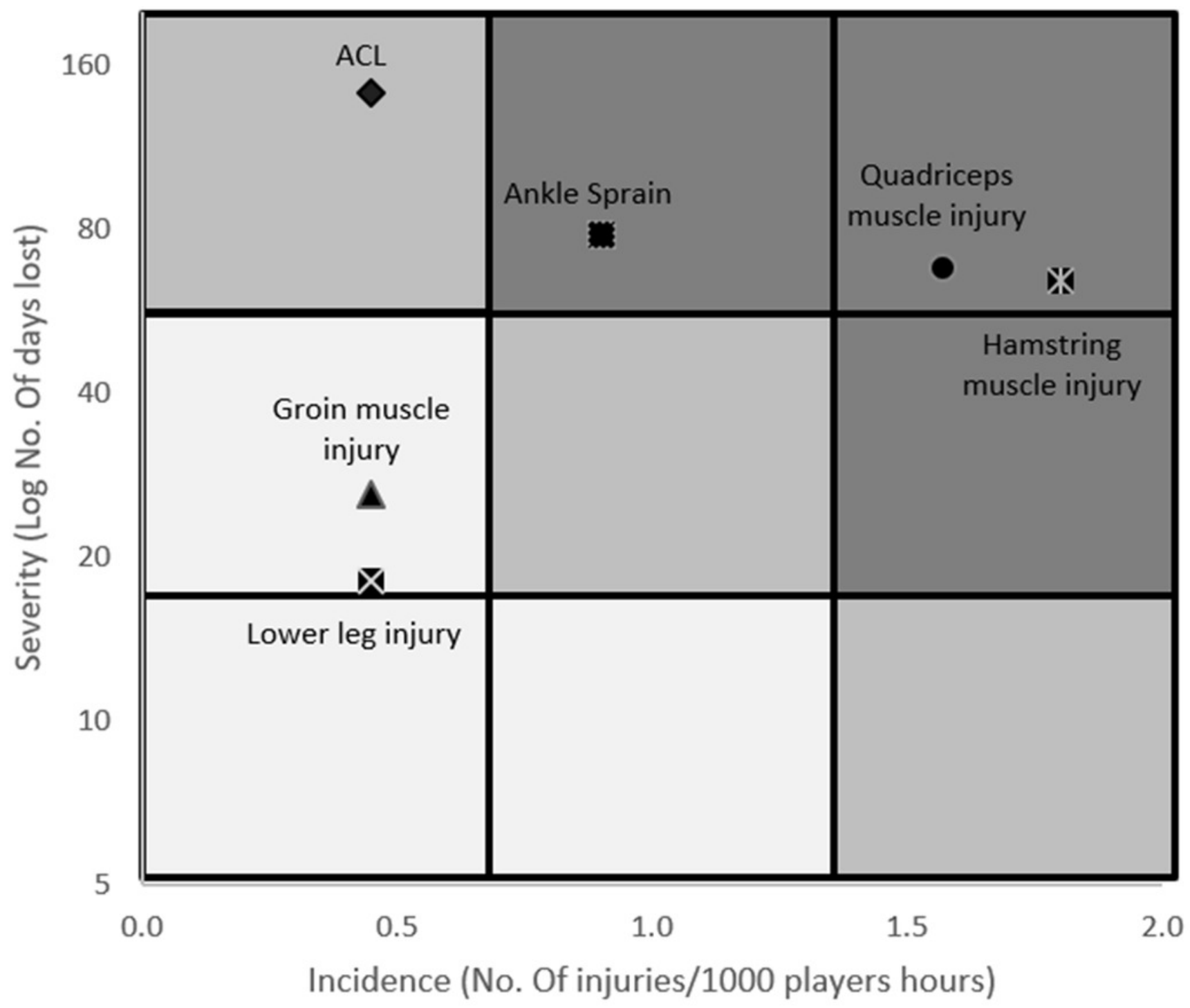


Figure 2

Distribution of total injury incidence

Distribution of total injury incidence

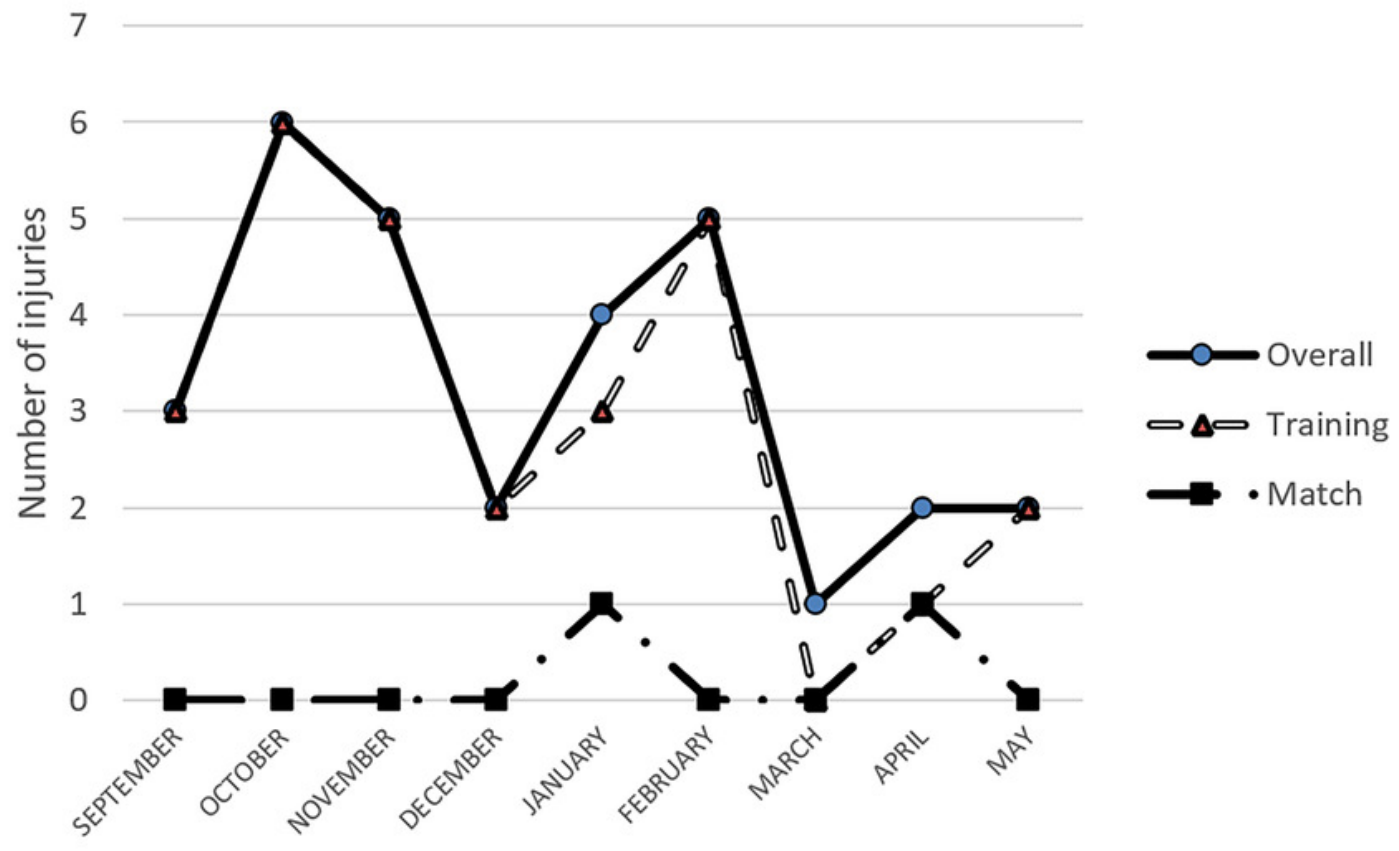




\section{Table 1 (on next page)}

Players and team characteristics and exposure time.

h: hours; a: match hours/total hours of exposure. Values are mean \pm SD. 
Table 1. Players and team characteristics and exposure time.

\begin{tabular}{lccccc}
\hline & Season 15/16 & Season 16/17 & Season 17/18 & Total & Mean \\
\hline Team size & $14(14)$ & $13(12)$ & $12(9)$ & $39(35)$ & $13 \pm 1$ \\
Age (years) & $23.8 \pm 2.9$ & $24.2 \pm 4.1$ & $24.2 \pm 4.8$ & - & $24.1 \pm 3.9$ \\
Height (cm) & $1.65 \pm 0.05$ & $1.65 \pm 0.04$ & $1.65 \pm 0.04$ & - & $1.65 \pm 0.04$ \\
Body mass (kg) & $60.4 \pm 5.1$ & $62.3 \pm 7.4$ & $61.9 \pm 7.4$ & - & $61.5 \pm 6.6$ \\
Weeks of follow-up & 32 & 35 & 36 & $34.3 \pm 2.1$ \\
Exoposure & & & 1610.7 & 4446.1 & $1482.1 \pm 142.6$ \\
Total h & 1506.7 & 1328.78 & 1500.7 & 4136.1 & $1378.8 \pm 142.5$ \\
Training h & 1413.3 & 1222.1 & 110 & 310 & $103.3 \pm 8.8$ \\
Match h & 93.3 & 106.7 & $3.8 \pm 0.5$ & - & 3.7 \\
Training sessions/week & $4 \pm 0.3$ & $3.2 \pm 0.7$ & 0.917 & - & 0.903 \\
Matches/week & 0.875 & 0.914 & 0.068 & - & 0.070 \\
Match exposure ratio & 0.062 & 0.080 & 51 & 429 & $143 \pm 91.5$ \\
Days of absence due to the injury & 234 & 144 & &
\end{tabular}

h: hours; a: match hours/total hours of exposure.

Values are mean \pm SD. 
Table 2 (on next page)

Table 2. Injury incidence

$\mathrm{Cl}$ : Confidence interval 
1 Table 2. Injury incidence

\begin{tabular}{|c|c|c|c|c|c|c|c|c|c|c|c|c|}
\hline \multirow[b]{2}{*}{ Injuries } & \multicolumn{3}{|c|}{ Season 15/16 } & \multicolumn{3}{|c|}{ Season 16/17 } & \multicolumn{2}{|c|}{ Season 17/18 } & \multirow[b]{2}{*}{$\begin{array}{l}\text { Injury } \\
\text { Burden }\end{array}$} & \multicolumn{3}{|c|}{ Total } \\
\hline & $\begin{array}{c}\text { Number } \\
(\%)\end{array}$ & $\begin{array}{l}\text { Incidence } \\
(95 \% \mathrm{Cl})\end{array}$ & $\begin{array}{c}\text { Injury } \\
\text { Burde } \\
\mathrm{n}\end{array}$ & $\begin{array}{c}\text { Number } \\
(\%)\end{array}$ & $\begin{array}{l}\text { Incidence } \\
(95 \% \mathrm{Cl})\end{array}$ & $\begin{array}{c}\text { Injury } \\
\text { Burde } \\
\mathrm{n}\end{array}$ & $\begin{array}{c}\text { Number } \\
(\%)\end{array}$ & $\begin{array}{l}\text { Incidence } \\
(95 \% \mathrm{Cl})\end{array}$ & & $\begin{array}{c}\text { Number } \\
\text { (\%) }\end{array}$ & $\begin{array}{l}\text { Incidence } \\
(95 \% \mathrm{Cl})\end{array}$ & $\begin{array}{c}\text { Injury } \\
\text { Burde } \\
n\end{array}$ \\
\hline Overall & 8 & $5.31(4.9-5.71)$ & 155.3 & 12 & $90.3(8.51-9.55)$ & 108.4 & 10 & 9.09 (8.93-9.25) & 31.7 & 30 & $6.75(6.47-7.02)$ & 96.5 \\
\hline Training & $8(100)$ & $\begin{array}{c}5.66(5.26- \\
6.06)\end{array}$ & 165.6 & $11(91.7)$ & $9.00(8.50-9.50)$ & 108.0 & $9(90)$ & $6.00(5.51-6.49)$ & 30.0 & $28(93.3)$ & $6.77(6.50-7.04)$ & 99.4 \\
\hline Match & $0(0)$ & 0 & 0 & $1(8.3)$ & $9.38(9.22-9.53)$ & 112.5 & $1(10)$ & $6.21(5.69-6.73)$ & 54.5 & $2(6.7)$ & $6.45(6.38-6.52)$ & 58.1 \\
\hline \multicolumn{13}{|l|}{ Mechanism } \\
\hline Traumatic training & $5(62.5)$ & $\begin{array}{c}3.32(3.01- \\
3.63)\end{array}$ & 145.4 & $8(66.7)$ & $6.02(5.59-6.45)$ & 87.3 & $7(70)$ & 4.35 (3.91-4.78) & 16.1 & $20(66.7)$ & $4.50(4.27-4.72)$ & 82.1 \\
\hline Traumatic match & $0(0)$ & 0 & 0 & $1(8.3)$ & & & $1(10)$ & & & $2(6.7)$ & & \\
\hline Overuse training & $3(37.5)$ & $\begin{array}{c}1.99(1.75- \\
2.23)\end{array}$ & 10 & $4(33.3)$ & $3.01(2.71-3.31)$ & 21.1 & $3(30)$ & $1.86(1.58-2.15)$ & 15.5 & $10(33.3)$ & $2.25(2.09-2.41)$ & 14.4 \\
\hline \multicolumn{13}{|l|}{ Circumstance } \\
\hline Contact & $0(0)$ & 0 & 0 & 0 & 0 & 0 & $2(20)$ & $1.24(1.01-1.47)$ & 5.6 & $2(6.7)$ & $0.45(0.38-0.52)$ & 2 \\
\hline Non-Contact & $8(100)$ & $\begin{array}{c}5.31(4.91- \\
5.71)\end{array}$ & 155.3 & $12(100)$ & $9.03(8.51-9.55)$ & 108.4 & $8(80)$ & $4.97(4.50-5.43)$ & 26.1 & $28(93.3)$ & $6.30(6.03-6.56)$ & 94.5 \\
\hline \multicolumn{13}{|l|}{ Recurrence } \\
\hline No & $8(100)$ & $\begin{array}{l}5.31(4.91- \\
5.71)\end{array}$ & 155.3 & $9(75)$ & $6.02(5.59-6.45)$ & 82.0 & $8(80)$ & $4.97(4.50-5.43)$ & 25.5 & $25(83.3)$ & $5.62(5.37-5.87)$ & 86.4 \\
\hline Yes & $0(0)$ & 0 & 0 & $3(25)$ & $2.26(2.00-2.52)$ & 26.3 & $2(20)$ & $1.24(1.01-1.47)$ & 6.2 & $5(16.7)$ & $1.12(1.01-1.24)$ & 10.1 \\
\hline Early & $0(0)$ & 0 & 0 & $1(33.3)$ & $0.75(0.60-0.90)$ & 12.0 & $0(0)$ & 0 & 0.0 & $1(20)$ & $0.22(0.17-0.28)$ & 3.6 \\
\hline Late & $0(0)$ & 0 & 0 & $2(66.7)$ & $1.51(1.29-1.72)$ & 14.3 & $1(50)$ & $0.62(0.46-0.78)$ & 1.9 & $3(60)$ & $0.67(0.59-0.76)$ & 4.9 \\
\hline Delayed & $0(0)$ & 0 & 0 & 0 & 0 & 0 & $1(50)$ & $0.62(0.46-0.78)$ & 4.3 & $1(20)$ & $0.22(0.17-0.28)$ & 1.6 \\
\hline \multicolumn{13}{|l|}{ Severity } \\
\hline 0 days & $0(0)$ & 0 & 0 & $0(0)$ & 0 & 0 & $0(0)$ & 0 & 0 & $0(0)$ & 0 & 0 \\
\hline Minimal (1-3 days) & $1(12.5)$ & $\begin{array}{c}0.66(0.52- \\
0.80)\end{array}$ & 2.0 & $2(16.7)$ & $1.51(1.29-1.72)$ & 4.5 & $5(50)$ & $3.10(2.74-3.47)$ & 6.8 & $8(26.7)$ & $1.80(1.66-1.94)$ & 4.5 \\
\hline Mild (4-7 days) & $2(25)$ & $\begin{array}{c}1.33(1.13- \\
1.53)\end{array}$ & 8.0 & $2(16.7)$ & $1.51(1.29-1.72)$ & 9.0 & $4(40)$ & $2.48(2.16-2.81)$ & 13.0 & $8(26.7)$ & $1.80(1.66-1.94)$ & 10.1 \\
\hline $\begin{array}{l}\text { Moderate (8-28 } \\
\text { days) }\end{array}$ & $4(50)$ & $\begin{array}{c}2.65(2.37- \\
2.93)\end{array}$ & 51.1 & $7(58.3)$ & $5.27(4.87-5.67)$ & 94.8 & $6(60)$ & $0.62(0.46-0.78)$ & 11.8 & $12(40)$ & $2.70(2.52-2.87)$ & 49.9 \\
\hline Severe (>28 days) & $1(12.5)$ & $\begin{array}{c}0.66(0.52- \\
0.80)\end{array}$ & 94.2 & $0(0)$ & 0 & 0 & $0(0)$ & 0 & 0 & $1(3.3)$ & $0.22(0.17-0.28)$ & 31.9 \\
\hline Career ending & $0(0)$ & 0 & 0 & $1(8.3)$ & $0.75(0.60-0.90)$ & - & $0(0)$ & 0 & 0 & $1(3.3)$ & $0.22(0.17-0.28)$ & - \\
\hline \multicolumn{13}{|l|}{ Position } \\
\hline Goalkeeper & $2(25)$ & $\begin{array}{c}1.33(0.40- \\
2.25)\end{array}$ & 16.6 & $2(16.7)$ & $1.51(0.12-2.89)$ & 7.5 & $0(0)$ & 0 & 0 & $4(13.3)$ & $0.90(0.34-1.46)$ & 7.9 \\
\hline Lastwoman & $4(50)$ & $\begin{array}{c}2.65(1.67- \\
3.63)\end{array}$ & 40.5 & $7(58.3)$ & $5.27(3.97-6.56)$ & 77.5 & $4(40)$ & $2.48(1.50-3.46)$ & 11.2 & $15(50)$ & $3.37(2.74-4.01)$ & 40.9 \\
\hline Wing & $0(0)$ & 0 & 0 & $3(25)$ & $2.26(1.58-2.94)$ & 23.3 & $6(60)$ & $3.73(2.52-4.93)$ & 20.5 & $9(30)$ & $2.02(1.57-2.48)$ & 14.4 \\
\hline
\end{tabular}




\begin{tabular}{llcccccccccccccc} 
Pivot & $2(25)$ & $\begin{array}{c}1.33(0.40- \\
2.02)\end{array}$ & 98.2 & $0(0)$ & 0 & 0 & $0(0)$ & 0 & $2(6.7)$ & $0.45(0.05-0.85)$ & 33.3 \\
\hline
\end{tabular}

2 Cl: Confidence interval. 


\section{Table 3(on next page)}

Injury characteristics and incidence according location and type of injury

$\mathrm{Cl}$ : Confidence interval. 
Table 3. Injury characteristics and incidence according location and type of injury.

\begin{tabular}{|c|c|c|c|c|c|c|c|c|c|c|c|c|c|}
\hline \multirow{2}{*}{\multicolumn{2}{|c|}{ Injury location }} & \multicolumn{3}{|c|}{ Season $15 / 16$} & \multicolumn{3}{|c|}{ Season 16/17 } & \multicolumn{3}{|c|}{ Season $17 / 18$} & \multicolumn{3}{|c|}{ Total } \\
\hline & & Number (\%) & Incidence $(95 \% \mathrm{Cl})$ & Injury Burden & Number (\%) & Incidence $(95 \% \mathrm{Cl})$ & Injury Burden & Number (\%) & Incidence $(95 \% \mathrm{Cl})$ & Injury Burden & Number (\%) & Incidence $(95 \% \mathrm{Cl})$ & Injury Burden \\
\hline \multirow[t]{3}{*}{ Upper limbs } & & $1(12.5)$ & $0.66(0.52-0.80)$ & 14.6 & $0(0)$ & 0 & 0 & $2(20)$ & $1.24(1.01-1.47)$ & 2.5 & $3(10)$ & $0.67(0.59-0.76)$ & 5.8 \\
\hline & Shoulder/clavicula & $0(0)$ & 0 & 0 & $0(0)$ & 0 & 0 & $1(10)$ & $0.62(0.46-0.78)$ & 0.6 & $1(3.3)$ & $0.22(0.17-0.28)$ & 0.2 \\
\hline & Hand/finger/thumb & $1(12.5)$ & $0.66(0.52-0.80)$ & 14.6 & $0(0)$ & 0 & 0 & $1(10)$ & $0.62(0.46-0.78)$ & 1.9 & $2(6.7)$ & $0.45(0.38-0.52)$ & 5.6 \\
\hline \multirow[t]{5}{*}{ Trunk } & & $1(12.5)$ & $0.66(0.52-0.80)$ & 2.0 & $0(0)$ & 0 & 0 & $1(10)$ & $0.62(0.46-0.78)$ & 2.5 & $2(6.7)$ & $0.45(0.38-0.52)$ & 0.7 \\
\hline & Lower back/pelvis/sacrum & $1(12.5)$ & $0.66(0.52-0.80)$ & 2.0 & $0(0)$ & 0 & 0 & $1(10)$ & $0.62(0.46-0.78)$ & 2.5 & $2(6.7)$ & $0.45(0.38-0.52)$ & 0.7 \\
\hline & & $6(75)$ & $3.98(3.64-4.33)$ & 138.7 & $12(100)$ & $9.03(8.51-9.55)$ & 108.4 & $7(70)$ & 4.35 (3.91-4.78) & 26.7 & $25(83.3)$ & $5.62(5.37-5.87)$ & 90.0 \\
\hline & Hip/groin/adductor & $0(0)$ & 0 & 0 & $1(8.3)$ & $0.75(0.60-0.90)$ & 16.6 & $1(10)$ & $0.62(0.46-0.78)$ & 2.5 & $2(6.7)$ & $0.45(0.38-0.52)$ & 5.8 \\
\hline & Thigh & $3(37.5)$ & $1.99(1.75-2.23)$ & 22.6 & $7(58.3)$ & $5.27(4.87-5.67)$ & 48.9 & $5(50)$ & $3.10(2.74-3.47)$ & 20.5 & $15(50)$ & $3.37(3.18-3.57)$ & 29.7 \\
\hline \multirow{5}{*}{ Lower limbs } & Hamstrings & $1(12.5)$ & $0.66(0.52-0.80)$ & 10.0 & $5(41.7)$ & $3.76(3.43-4.10)$ & 33.1 & $2(20)$ & $1.24(1.01-1.47)$ & 3.1 & $8(26.7)$ & $1.80(1.66-1.94)$ & 14.4 \\
\hline & Quadriceps & $2(25)$ & $1.33(1.13-1.53)$ & 12.6 & $2(16.7)$ & $1.51(1.29-1.72)$ & 15.8 & $3(30)$ & $1.86(1.58-2.15)$ & 17.4 & $7(23.3)$ & $1.57-1.44-1.71)$ & 15.3 \\
\hline & Knee & $1(12.5)$ & $0.66(0.52-0.80)$ & 94.2 & $1(8.3)$ & $0.75(0.60-0.90)$ & 0 & $0(0)$ & 0.0 & 0 & $2(6.7)$ & $0.45(0.38-0.52)$ & 31.9 \\
\hline & Lower leg/Achilles tendon & $1(12.5)$ & $0.66(0.52-0.80)$ & 4.0 & $1(8.3)$ & $0.75(0.60-0.90)$ & 9.0 & $0(0)$ & 0.0 & 0 & $2(6.7)$ & $0.45(0.38-0.52)$ & 4.0 \\
\hline & Ankle & $1(12.5)$ & $0.66(0.52-0.80)$ & 17.9 & $2(16.7)$ & $1.51(1.29-1.72)$ & 33.9 & $1(10)$ & $0.62(0.46-0.78)$ & 3.7 & $4(13.3)$ & $0.90-(0.80-1.00)$ & 17.5 \\
\hline \multicolumn{14}{|c|}{ Injury type } \\
\hline Fracture and & bone stress & 0 & 0 & 0 & 0 & 0 & 0 & $1(10)$ & $0.62(0.46-0.78)$ & 1.9 & $1(3.3)$ & $0.22(0.17-0.28)$ & 0.7 \\
\hline & Fracture & 0 & 0 & 0 & 0 & 0 & 0 & $1(10)$ & $0.62(0.46-0.78)$ & 1.9 & $1(3.3)$ & $0.22(0.17-0.28)$ & 0.7 \\
\hline Joint (non-bor & ne) and ligament & $3(37.5)$ & $1.99(1.75-2.23)$ & 126.8 & $2(16.7)$ & $1.51(1.29-1.72)$ & 21.1 & $1(10)$ & $0.62(0.46-0.78)$ & 0.6 & $6(20)$ & $1.35(1.23-1.47)$ & 49.5 \\
\hline & Sprain/Ligament injury & $3(37.5)$ & $1.99(1.75-2.23)$ & 126.8 & $2(16.7)$ & $1.51(1.29-1.72)$ & 21.1 & $1(10)$ & $0.62(0.46-0.78)$ & 0.6 & $6(20)$ & $1.35(1.23-1.47)$ & 49.5 \\
\hline Muscle and te & endon & $5(62.5)$ & $3.32(3.01-3.63)$ & 28.5 & $10(83.3)$ & $7.53(7.05-8)$ & 87.3 & $7(70)$ & $4.35(3.91-4.78)$ & 25.5 & $22(73.4)$ & $4.95(4.71-5.18)$ & 45.0 \\
\hline & Muscle rupture/tear/strain/cramps & $4(50)$ & $2.65(2.37-2.93)$ & 24.6 & $9(75)$ & $6.77(6.32-7.23)$ & 74.5 & $7(70)$ & $4.35(3.91-4.78)$ & 25.5 & $20(66.7)$ & $4.5(4.27-4.72)$ & 39.8 \\
\hline & Tendon injury/rupture/tendinosis/bursitis & $1(12.5)$ & $0.66(0.52-0.80)$ & 4 & $1(8.3)$ & $0.75(0.60-0.90)$ & 12.8 & 0 & 0 & 0 & $2(6.7)$ & $0.45(0.38-0.52)$ & 5.2 \\
\hline
\end{tabular}

